\title{
Exposure to a Mycobacterial Antigen, ESAT-6, Exacerbates Granulomatous and Fibrotic Changes in a Multiwall Carbon Nanotube Model of Chronic Pulmonary Disease
}

Anagha Malur ${ }^{1}$, Barbara P Barna', Janki Patel'1, Matthew McPeek¹, Christopher J Wingard ${ }^{2}$, Larry Dobbs ${ }^{3}$ and Mary Jane Thomassen ${ }^{1 *}$

${ }^{1}$ Program in Lung Cell Biology and Translational Research, Division of Pulmonary, Critical Care and Sleep Medicine, East Carolina University, Greenville, NC, USA ${ }^{2}$ Department of Physiology, East Carolina University, Greenville, NC, USA

${ }^{3}$ Department of Pathology, East Carolina University, Greenville, NC, USA

\begin{abstract}
Recent studies suggest additive effects of environmental pollutants and microbial antigens on respiratory disease. We established a granuloma model in which instilled multiwall carbon nanotubes (MWCNT) elicit granulomatous pathology. We hypothesized that mycobacterial antigen ESAT-6, a T cell activator associated with tuberculosis and sarcoidosis, might alter pathology. Wild-type C57BI/6 mice received MWCNT with or without ESAT-6 peptide. Controls received vehicle (surfactant-PBS) or ESAT-6 alone. Mice were evaluated 60 days later for granulomas, fibrosis, and bronchoalveolar lavage (BAL) cell expression of inflammatory mediators (CCL2, MMP-12, and Osteopontin). Results indicated increased granulomas, fibrosis, and inflammatory mediators in mice receiving the combination of MWCNT+ESAT-6 compared to MWCNT or vehicle alone. ESAT-6 alone showed no significant effect on these pathological endpoints. However, CD3 (+) lymphocyte infiltration of lung tissue increased with MWCNT+ESAT-6 versus MWCNT alone. Findings suggest that concurrent exposure to microbial antigen and MWCNT exacerbates chronic pulmonary disease.
\end{abstract}

Keywords: Granuloma; Carbon nanotube; Mycobacterial antigen; Fibrosis

\section{Background}

Carbon-based nanomaterials are naturally present within our environment but also constitute an important segment of industrially manufactured consumer products [1-4]. Within the environment, the importance and impact of carbon particles might be underestimated as causative agents and/or factors involved in the development of respiratory diseases. Experimental animals exposed to carbon nanotubes show persistence of nanotubes in vivo and in some cases, develop pulmonary granuloma-like lesions [5-7]. In other cases, carbon nanotubes may elicit other fibrotic changes $[8,9]$.

In order to explore pathophysiologic mechanisms of granuloma formation and persistence, we developed a novel multiwall carbon nanotube (MWCNT) model of granulomatous disease [10]. MWCNTelicited granulomatous disease is chronic (where granulomas persist up to 90 days), and is characterized by persistently elevated pro-inflammatory cytokines together with $\mathrm{T}$ cell and macrophage recruitment - all traits found in sarcoidosis, a human granulomatous disease of unknown etiology [11]. Epidemiologic studies have linked sarcoidosis to some environmental risk factors that favor carbon nanotube formation in ambient air. Examples include exposure to wood-burning stoves, fireplaces, or firefighting [12-15].

Other reports have led to the possibility that mycobacterial products may also play a role in sarcoidosis [16]. Studies in sarcoidosis patients have detected T cell reactivity to peptide components of Early Secreted Antigenic Target Protein 6 (ESAT-6), a Mycobacterium tuberculosis secreted protein $[17,18]$. Production of interferon gamma (IFN- $\gamma$ ) by peripheral blood cells in response to ESAT- 6 together with other peptide components of $M$. tuberculosis also forms the basis of clinical tests for detection of latent tuberculosis infection $[19,20]$. Administration of an ESAT-6 fusion protein has been shown to protect against $M$. tuberculosis infection in mice [21] but the possible effects of ESAT-6 exposure in association with a non-infectious, environmental pulmonary challenge such as MWCNT have not been explored. We hypothesized that concurrent administration of ESAT- 6 with MWCNT might exacerbate MWCNT-mediated granulomatous disease.

\section{Materials and methods}

\section{MWCNT model}

All studies were conducted in conformity with Public Health Service (PHS) Policy on humane care and use of laboratory animals and were approved by the institutional animal care committee. C57BL/6J wild-type mice received an oropharyngeal instillation of MWCNT after sedation with isofluorane. MWCNTs (catalogue number 900-1501, lot GS1801, SES Research, Houston, TX) were freshly prepared and have been extensively described previously [10,22]. A single pulmonary instillation of MWCNT $(100 \mu \mathrm{g})$ in $\mathrm{PBS} / 35 \%$ surfactant (vehicle) \pm ESAT-6 peptide 14 (NNALQNLARTISEAG) $(20 \mu \mathrm{g})$ were delivered to wild-type C57Bl/6 mice. Sham controls received vehicle alone; additional controls received only ESAT-6. Animals were sacrificed at 60 days post instillation for evaluation of lung tissue histopathology, laser capture microdissection (LCM) of granulomas, and bronchoalveolar lavage (BAL) cells as previously described [22].

*Corresponding author: Mary Jane Thomassen, Program in Lung Cell Biology and Translational Research Division of Pulmonary and Critical Care Medicine East Carolina University, 3E-149 Brody Medical Sciences Building, Greenville, NC 27834, USA, Tel: 1-252-744-1117; E-mail: thomassenm@ecu.edu

Received December 09, 2015; Accepted December 17, 2015; Published December 27, 2015

Citation: Malur A, Barna BP, Patel J, McPeek M, Wingard CJ, et al. (2015) Exposure to a Mycobacterial Antigen, ESAT-6, Exacerbates Granulomatous and Fibrotic Changes in a Multiwall Carbon Nanotube Model of Chronic Pulmonary Disease. J Nanomed Nanotechnol 6: 340. doi:10.4172/2157-7439.1000340

Copyright: ( 2015 Malur A, et al. This is an open-access article distributed under the terms of the Creative Commons Attribution License, which permits unrestricted use, distribution, and reproduction in any medium, provided the original author and source are credited. 
Citation: Malur A, Barna BP, Patel J, McPeek M, Wingard CJ, et al. (2015) Exposure to a Mycobacterial Antigen, ESAT-6, Exacerbates Granulomatous and Fibrotic Changes in a Multiwall Carbon Nanotube Model of Chronic Pulmonary Disease. J Nanomed Nanotechnol 6 : 340. doi:10.4172/2157-7439.1000340

Page 2 of 6

\section{Characterization of bronchoalveolar lavage (bal) cells}

Leukocyte differential counts of BAL cells were calculated from cytospins $(100$ cells $/ 40 \times$ high power field $\times 3$ fields $)$ as previously described [10]. Aliquots of BAL cells were centrifuged and frozen for qPCR evaluation as previously described [23]. Total RNA was extracted from BAL cells by RNeasy protocol (Qiagen, Valencia, CA). Expression of mRNA was determined by real time qPCR using the ABI Prism 7300 Detection System (TaqMan; Applied Biosystems, Foster City, CA.). Primer-probe sets for CCL2 (MCP1), CCL4 (MIP1 $\beta$ ), Fibronectin 1 (Fn1), IFN- $\gamma$, PPAR $\gamma$, Matrix Metalloproteinase-12 (MMP12), osteopontin (OPN), CD3e, and the GAPDH housekeeping gene were obtained from Qiagen, Germantown, MD. Data were expressed as fold change in mRNA expression compared to control values as previously described [10]. Levels of OPN protein in BAL fluid were determined by ELISA assay (R\&D Systems, Inc., Minneapolis, MN).

\section{Histological analysis}

Lungs were dissected and fixed in PBS 10\% formalin. A semiquantitative scoring system previously described [22] was used for a relative comparison of the numbers and quality of the granulomas formed in MWCNT versus ESAT-6 + MWCNT instilled mice. Hematoxylin and Eosin stained sections of lung from each of the experimental mice was assigned a score of between 0 and 5 by two independent investigators using the following scoring system: (score 0) - no granulomas or aggregates of macrophages seen; (score 1) - few small groups of macrophages but no well-formed granulomas; (score 2) - scattered small granulomas not easily seen on scanning power (20X); (score 3 ) - scattered small granulomas easily seen on scanning power (20X); (score 4) - scattered small granulomas with occasional larger granulomas seen on scanning power (20X); (score 5) - numerous large granulomas easily seen on scanning power. The scores obtained by the two investigators were averaged for the final analysis.

\section{Immunohistochemistry}

Frozen lung tissue sections $(7 \mu \mathrm{M})$ were fixed with $4 \%$ paraformaldehyde-PBS, permeabilized with Triton X-100, and stained with anti-CD3 antibody (Abcam, Cambridge, MA) at 1:100 dilution, followed by Alexa conjugated goat anti rabbit IgG (Invitrogen, Carlsbad, CA). Slides were counter stained with DAPI (Vector Laboratories, Burlingame, CA) to facilitate nuclear localization. Formalin fixed, paraffin embedded lung tissue sections were stained for Masson's Trichrome stain (Provia Diagnostics, Greenville, NC)

\section{Statistical analyses}

Data were analyzed by student's $t$ test or one-way analysis of variance (ANOVA) and Tukey's test using Prism software (GraphPad, Inc., San Diego, CA.).

\section{Results}

\section{ESAT-6 exacerbates granulomatous changes}

No granulomas were detected in animals receiving sham treatment (Figure 1A) or ESAT-6 alone (Figure 1B). Compared to animals receiving MWCNT alone (Figure 1C), granulomatous changes were more extensive in mice receiving MWCNT + ESAT-6 (Figure 1D). Evaluation of granulomas by a semi-quantitative scoring scale indicated significantly increased $(\mathrm{p} \leq 0.05)$ foci in mice receiving MWCNT + ESAT-6 compared to mice receiving MWCNT alone (Figure 1E).

\section{ESAT-6 elicits fibrosis}

Our previous MWCNT studies utilized trichrome staining but detected no fibrosis after instillation of MWCNT alone [10]. Trichrome staining in the current study revealed marked fibrotic changes within granulomas of mice receiving MWCNT + ESAT 6 (Figure 2D) as compared to granulomas of mice receiving only MWCNT (Figure 2C). No fibrosis was detectable in mice receiving sham treatment (Figure

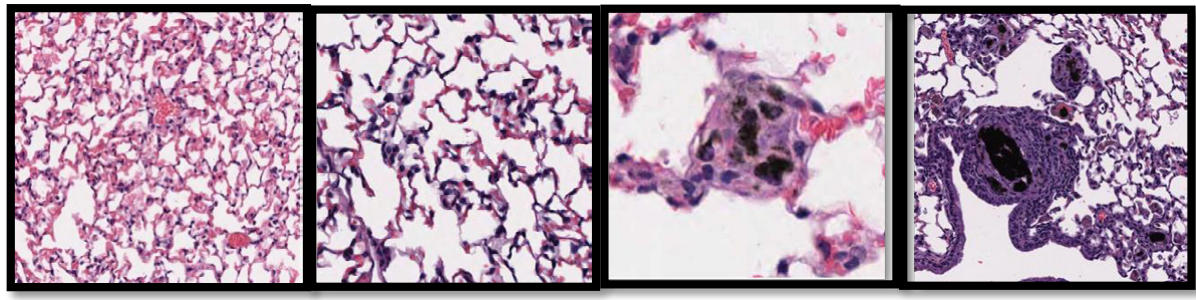
A. SHAM
B. ESAT-6
C. MWCNT
D. MWCNT+ESAT

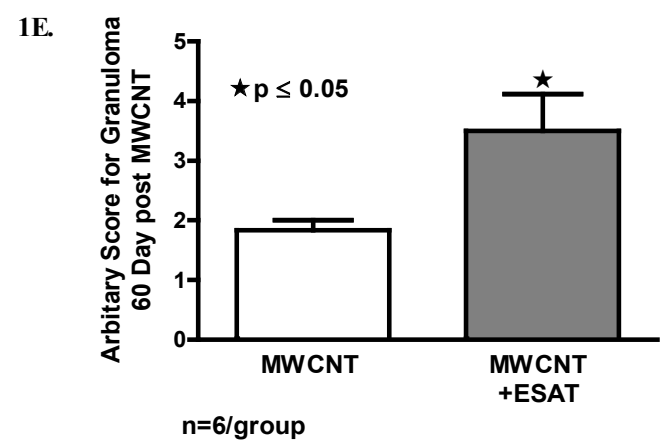

Figure 1: ESAT-6 exacerbates granulomatous changes. Figures show representative sections of lung from each treatment or control group (Hematoxylin and Eosin, $200 x$ ) ( $n=3 /$ group). No granulomas were detected in either Sham-treated controls (A) or mice treated with ESAT-6 alone (B). Granulomas are visible in mice instilled with MWCNT $(C)$ and are more frequent in mice instilled with the combination of MWCNT + ESAT-6 (D). Analysis by a semi-quantitative scoring system indicated significant $(p \leq 0.05)$ elevation of granulomatous changes in mice receiving MWCNT + ESAT-6 compared to those receiving MWCNT alone (E). 
Citation: Malur A, Barna BP, Patel J, McPeek M, Wingard CJ, et al. (2015) Exposure to a Mycobacterial Antigen, ESAT-6, Exacerbates Granulomatous and Fibrotic Changes in a Multiwall Carbon Nanotube Model of Chronic Pulmonary Disease. J Nanomed Nanotechnol 6 : 340. doi:10.4172/2157-7439.1000340

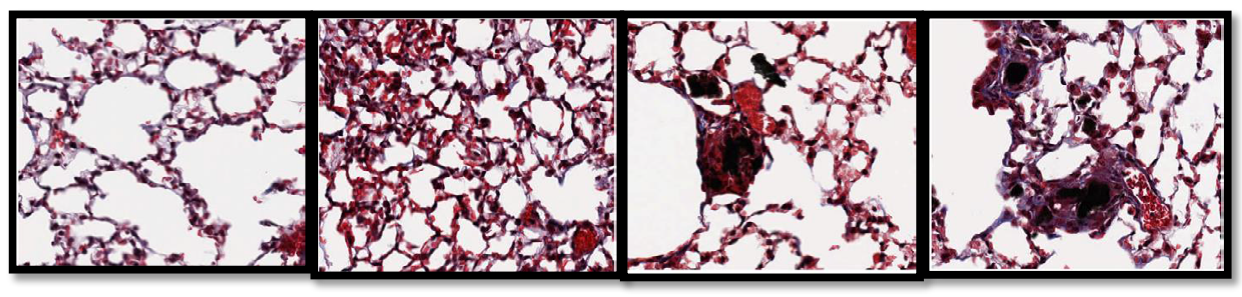

A. SHAM

B. ESAT

C. MWCNT

D. MWCNT+ESAT

2E.

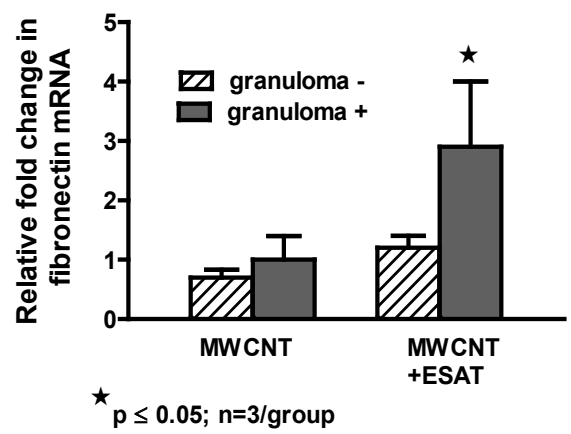

Figure 2: ESAT-6 increases fibrosis. Figures show representative sections of lung from each treatment or control group (Trichrome, 200x) ( $n=3 /$ group). No fibrotic changes were present in either sham-treated controls (A) or mice receiving ESAT-6 alone (B). Mice instilled with MWCNT alone exhibited little fibrosis in granuloma and non-granuloma areas (C). The combination of MWCNT + ESAT-6, however elicited marked fibrosis: the trichrome stain highlights the presence of collagen fibers (stained blue) associated with granulomas (D). qPCR analysis of lung tissues obtained by LCM revealed significant $(p \leq 0.05)$ elevation of fibronectin (Fn1) in granuloma (+) tissue from mice instilled with MWCNT + ESAT-6 compared to granuloma (-) tissue (E).

2A) or ESAT-6 alone (Figure 2B). To examine fibrotic changes further, fibronectin 1 (Fn1) mRNA expression was evaluated in LCM sections of lung tissue (Figure 2E). Fn1 was significantly ( $\mathrm{p} \leq 0.05$ ) elevated in granuloma-positive tissue from MWCNT + ESAT-6 instilled lung compared to granuloma-negative within the same lung. However, granuloma-positive tissue from MWCNT-instilled lung was not different from granuloma-negative (Figure 2E).

\section{ESAT-6 increases CD3 (+) cells within lung tissue but not BAL}

Because lymphocyte reactivity to ESAT- 6 has been reported in human granulomatous disease (tuberculosis and sarcoidosis) [24], we evaluated lymphocyte distribution and reactivity in mice exposed to ESAT-6 combined with MWCNT. Examination of BAL cell differential counts indicated no significant changes related to ESAT-6 instillation either alone or in combination with MWCNT compared to sham-treated mice (all groups had $>95 \%$ alveolar macrophages). As reported in previous MWCNT studies, BAL lymphocyte counts were not significantly altered by MWCNT instillation compared to sham controls [10]. By immunohistochemistry, no CD3 (+) T lymphocytes were detected in lungs of mice receiving vehicle (data not shown) or ESAT-6 alone (Figures 3A and 3B) but CD3 (+) cells were visualized on the periphery of MWCNT-containing granulomatous structures within lung tissues of mice instilled with MWCNT as previously described [10] (Figures 3C and 3D). Compared to MWCNT alone, CD3 $(+)$ cells were more prevalent around granulomas in lung tissues from mice instilled with MWCNT + ESAT-6 (Figures 3E and 3F). To further examine CD3 expression, qPCR was used to quantitate CD3e mRNA within LCM sections of lung tissue (Figure 3G). CD3e was significantly $(\mathrm{p} \leq 0.05)$ elevated in non-granulomatous tissues compared to granulomatous tissues in either MWCNT or MWCNT+ESAT-6 instilled mice. The highest levels of $\mathrm{CD} 3 \mathrm{e}$, however were noted in mice receiving MWCNT+ESAT-6 versus mice receiving only MWCNT ( $\mathrm{p} \leq$ 0.05) (Figure 3G).

\section{Increase of inflammatory mediators in BAL by ESAT-6}

Because our previous studies had indicated elevated production of chemokines and other inflammatory mediators in BAL cells in response to MWCNT instillation [10], the effects of ESAT-6 on such mediators were examined. Results indicated that addition of ESAT-6 to MWCNT resulted in a marked increase in BAL production of OPN, a key factor in granuloma formation [25] (Figure 4A). BAL cell OPN mRNA expression in mice instilled with MWCNT + ESAT-6 was significantly ( $\mathrm{p} \leq 0.05)$ higher $(7.1$-fold) than that of MWCNT alone (3.5-fold) (Figure 4A). OPN in ESAT-6 alone did not differ from that of sham controls (Figure 4A). Examination of OPN protein in BAL fluid confirmed this pattern: levels in MWCNT+ ESAT- 6 were significantly higher than levels with MWCNT alone (Figure 4B). OPN in mice receiving only ESAT- 6 was not different from that of sham controls (Figure 4B)

Similarly, expression levels of the chemokine, CCL2, were also dramatically and significantly $(\mathrm{p}<0.05)$ elevated $(34.3$-fold $)$ by the combination of MWCNT + ESAT- 6 compared to MWCNT alone (4-fold) (Figure 4C). BAL cell CCL2 mRNA levels with ESAT-6 alone did not differ from those of sham controls (Figure 4C). Examination of BAL cell MMP-12 mRNA expression also revealed a significant ( $\mathrm{p}$ $\leq 0.05)$ increase (27.9-fold) in levels from MWCNT+ESAT-6 instilled mice compared to levels in MWCNT instillation alone (11.3-fold) (Figure 4D). MMP-12 levels in mice receiving ESAT-6 alone did not differ from those of sham controls (Figure 4D).

\section{Decline of interferon- $\gamma$ expression by ESAT-6}

Based upon previous studies showing that ESAT-6 may elicit IFN- $\gamma$ expression in sensitized animals $[21,26]$, we evaluated IFN- $\gamma$ mRNA expression in BAL cells of mice at 60 days after instillation of MWCNT with or without ESAT-6 (Figure 5). Compared to sham controls, BAL cell IFN- $\gamma$ mRNA expression was significantly $(\mathrm{p}<0.05)$ elevated 
Citation: Malur A, Barna BP, Patel J, McPeek M, Wingard CJ, et al. (2015) Exposure to a Mycobacterial Antigen, ESAT-6, Exacerbates Granulomatous and Fibrotic Changes in a Multiwall Carbon Nanotube Model of Chronic Pulmonary Disease. J Nanomed Nanotechnol 6 : 340. doi:10.4172/2157-7439.1000340

Page 4 of 6

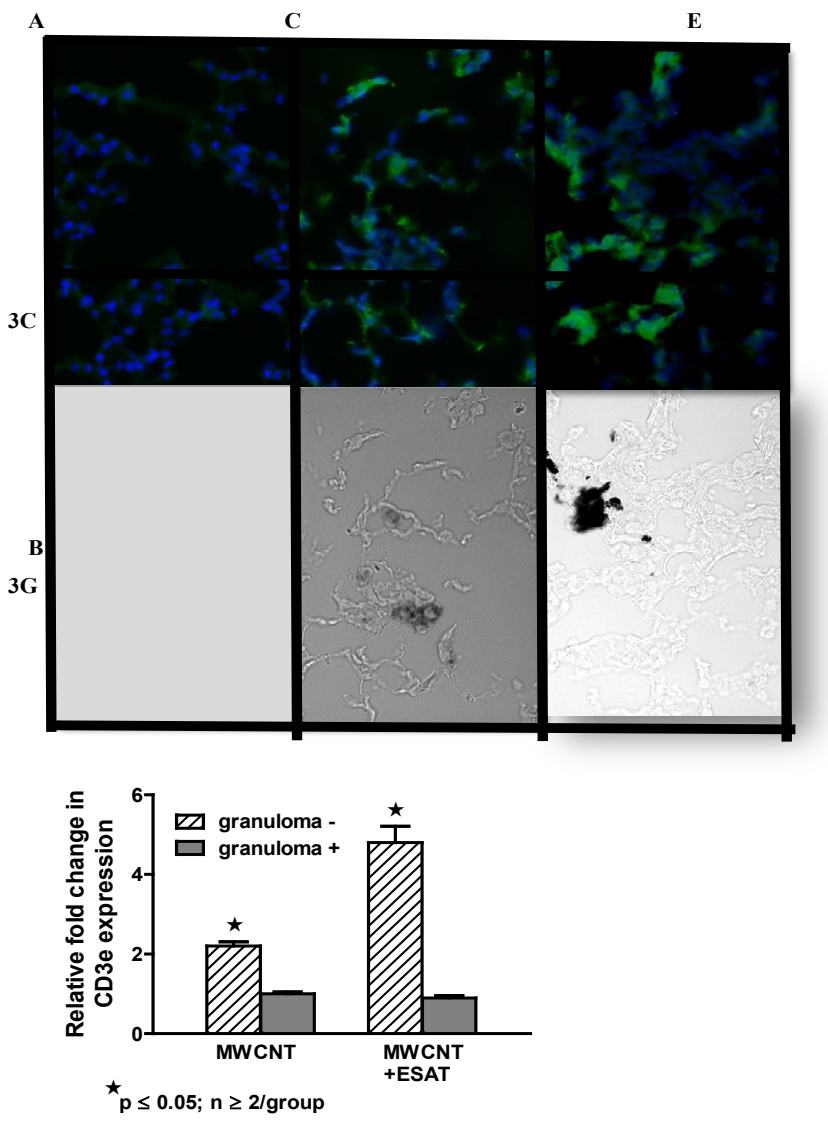

Figure 3: CD3 (+) lymphocytes are elevated in MWCNT+ESAT-6 lung tissue. Figures show representative areas from bright field and corresponding dark field views of fluorescently stained (anti-CD3 plus Alexa-conjugated second antibody followed by counterstain with DAPI) lung sections from mice instilled with: ESAT-6 alone (A, B); MWCNT $(C, D)$ and MWCNT + ESAT-6 (E, F) (n=3/group). No MWCNT or CD3+ cells are visible in lung sections from mice receiving ESAT-6 alone (A B). In lung sections from animals instilled with MWCNT alone, CD3 (+) cells are visible in dark field (C) and MWCNT can be seen in bright field (D). Similarly, lung sections from mice receiving MWCNT + ESAT-6 show MWCNT in bright field (F) with increased numbers of CD3 $(+)$ cells in dark field $(E)$ compared to MWCNT alone $(C)$. (G). Expression of CD3e mRNA by qPCR shows significant elevation $(p \leq 0.05)$ in granuloma $(-)$ versus granuloma (+) tissues. The highest CD3e elevation can be seen in MWCNT+ESAT- 6 granuloma (-) tissue compared to granuloma (-) tissue from MWCNT alone $(p \leq 0.05)$.

in mice receiving either MWCNT alone or MWCNT+ESAT-6. Surprisingly, IFN- $\gamma$ expression was reduced after MWCNT + ESAT- 6 instillation rather than increased as were other BAL cell inflammatory mediators. There was no significant difference between MWCNT (8fold) and MWCNT + ESAT-6 (5.7 fold) IFN- $\gamma$ levels. In mice receiving only ESAT-6, IFN- $\gamma$ expression was not elevated and was comparable to that of sham controls (Figure 5).

\section{Increase of PPAR $\gamma$ expression by ESAT-6}

Our previous studies noted that MWCNT-mediated granulomatous inflammation was exacerbated in mice with macrophage-specific PPAR $\gamma$ deficiency [22], therefore it was of interest to determine whether ESAT-6 effects were associated with reduced PPAR $\gamma$ expression. Results indicated that addition of ESAT- 6 to MWCNT did not further reduce PPAR $\gamma$ mRNA expression in BAL cells (Figure 6). As noted previously [22], PPAR $\gamma$ mRNA expression became significantly ( $\mathrm{p} \leq$
0.05) depressed in BAL cells from mice instilled with MWCNT $(26 \%$ of sham control level) while addition of ESAT- 6 to MWCNT reduced
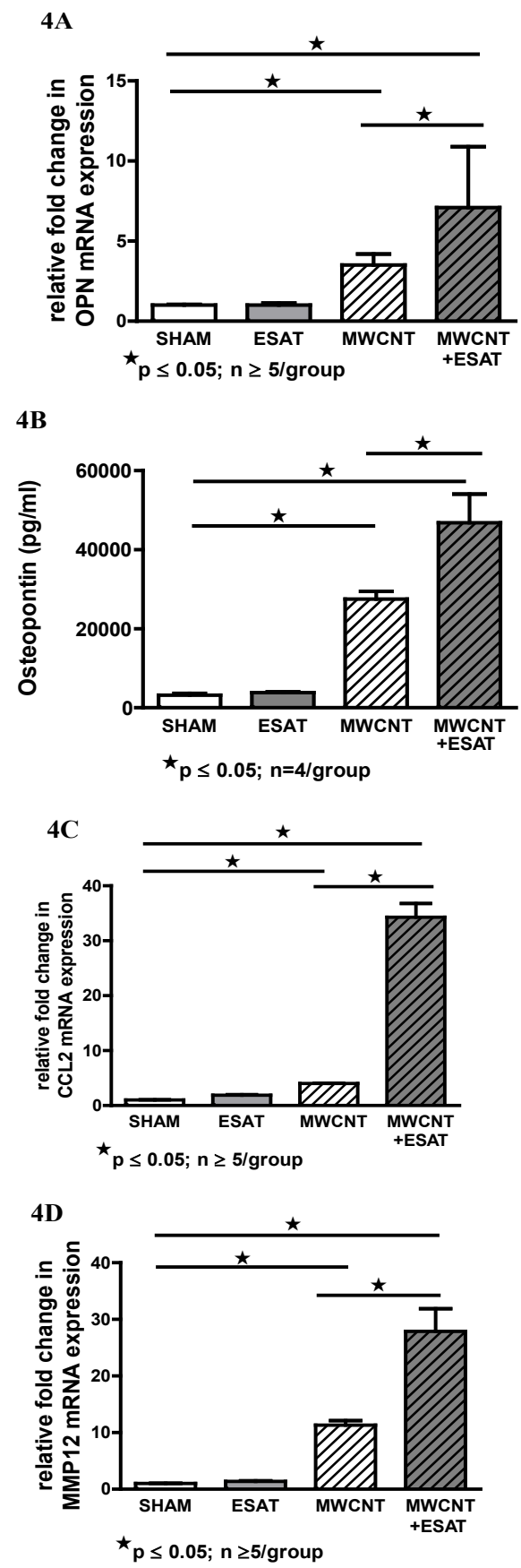

Figure 4: BAL cell expression of inflammatory mediators is increased by ESAT-6. OPN mRNA expression in response to MWCNT was significantly $(p \leq 0.05)$ doubled by addition of ESAT-6. OPN expression in response to ESAT-6 alone did not differ from sham controls (A). Similarly OPN protein in BAL fluid was significantly $(p<0.05)$ elevated in MWCNT + ESAT-6 compared to MWCNT alone. OPN in ESAT-6 alone was comparable to sham controls (B). BAL cell mRNA expression of the chemokine, CCL2 was elevated $(p<0.05)$ in mice instilled with MWCNT + ESAT-6 compared to mice receiving only MWCNT. There was no difference in CCL2 expression between sham controls and mice receiving only ESAT-6 (C). BAL cell mRNA expression of MMP12 was significantly $(\mathrm{p} \leq 0.05)$ increased in mice instilled with MWCNT + ESAT-6 compared to mice receiving only MWCNT. MMP-12 expression in ESAT-6 alone did not differ from that of sham control (D). 
Citation: Malur A, Barna BP, Patel J, McPeek M, Wingard CJ, et al. (2015) Exposure to a Mycobacterial Antigen, ESAT-6, Exacerbates Granulomatous and Fibrotic Changes in a Multiwall Carbon Nanotube Model of Chronic Pulmonary Disease. J Nanomed Nanotechnol 6 : 340. doi:10.4172/2157-7439.1000340

Page 5 of 6

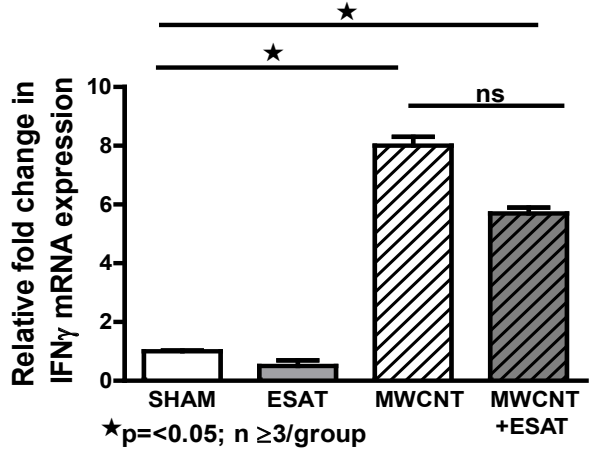

Figure 5: BAL cell expression of Interferon-y expression is not enhanced by ESAT-6. IFN-y mRNA ascertained by qPCR was comparably and significantly $(p \leq 0.05)$ elevated in MWCNT and MWCNT + ESAT-6 compared to sham controls. IFN-y was undetectable in BAL cells from mice receiving ESAT-6 alone.

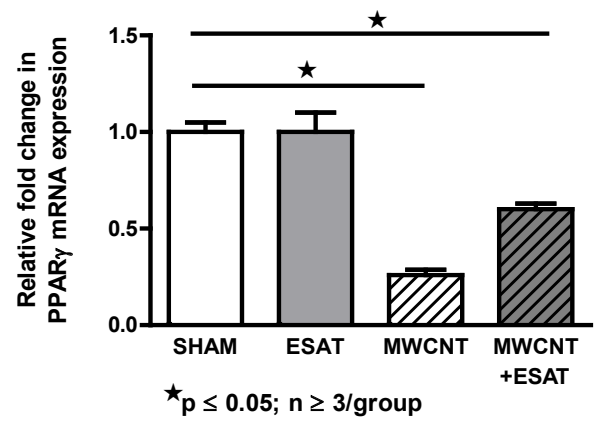

Figure 6: BAL cell expression of PPARY is not further decreased by ESAT6. PPARy expression was significantly $(\mathrm{p} \leq 0.05)$ lower than that of sham controls in mice receiving MWCNT or MWCNT + ESAT-6. There was not a significant difference, however between MWCNT versus MWCNT + ESAT6 groups. There was no difference in PPARY expression between sham controls and mice receiving only ESAT-6.

PPAR $\gamma$ expression to only $60 \%$ of sham control level (Figure 6). Both values were significantly ( $\mathrm{p} \leq 0.05$ ) lower than sham control values but were not different from each other. ESAT- 6 alone had no effect and was comparable to sham control.

\section{Discussion}

Findings indicate that concurrent instillation of ESAT- 6 with MWCNT adversely modifies the pathophysiology of pulmonary granulomatous disease by expanding the extent of granulomatous involvement and introducing fibrotic changes. In our previous studies utilizing only MWCNT, a $100 \mu \mathrm{g}$ dose was selected as a dose most consistently eliciting granulomas as early as 10 days post instillation [10]. Trichrome staining in those studies did not reveal fibrotic changes. Surprisingly, the addition of ESAT-6 to MWCNT generated marked fibrosis as shown by both Masson Trichrome stain and by elevated fibronectin expression within granulomas. Other MWCNT animal studies have reported rapid development of pulmonary fibrosis by 1-7 days post exposure and persistence through 56 days post exposure $[8,27]$. Because our focus is to understand mechanisms operating within a chronic MWCNT disease model, we did not run early time points within the current study as in our initial paper [10]. However, our current results warrant future studies to determine whether the fibrotic effects of ESAT -6 can be detected within an acute inflammatory time period (1-10 days) or are more representative of a delayed response.
By both immunohistochemistry and qPCR, CD3-positive lymphocytes appeared to be more concentrated within pulmonary granulomatous tissues following instillation of combined ESAT-6 and MWCNT than following instillation of MWCNT alone. No CD3 positive cells were apparent with ESAT-6 alone. As noted in previous immunohistochemical findings [10], CD3-positive cells occur adjacent to granulomatous structures rather than within the granulomas themselves. Interestingly, our findings are consistent with previous murine studies of ESAT- 6 which indicated that higher numbers of T cells were present in lymph nodes and lung after administration of a microparticle-encapsulated ESAT-6 compared to administration of free ESAT-6 alone which resembled results from untreated controls [26]. Such data suggest the possibility that MWCNT in our study may have functioned as carriers for enhancing ESAT-6 presentation within lung tissue and consequently lymphocytic infiltration. In latent $M$ tuberculosis, $\mathrm{T}$ lymphocytes are also elevated within granulomatous lung tissue and are ESAT- 6 responsive (i.e. produce IFN- $\gamma$ ) [28]. Our studies, however, did not find that IFN- $\gamma$ responses in mice instilled with MWCNT + ESAT- 6 were greater than those with MWCNT alone. Reduced production of IFN $-\gamma$ may be related to $\mathrm{T}$ cell immunophenotype. In sarcoidosis, $\mathrm{T}$ cells with a Th-17 immunophenotype are present in BAL fluid but exhibit reduced IFN- $\gamma$ responses compared to controls [29].

Some of the most striking data in this study stemming from the inclusion of ESAT-6 with MWCNT were the markedly increased levels of OPN, CCL2, and MMP-12 in BAL cells compared to MWCNT instillation alone. The multifunctional cytokine, OPN, is associated with extracellular matrix signaling and has been cited as necessary for both granuloma formation and fibrosis [30,31]. MMP-12, a metalloelastase, plays a role in several pulmonary fibrosis models [25,32]. The chemokine, CCL2, has also been associated with lung fibrosis models and blockade of CCL2 has been shown to reduce fibrosis [33]. Data show that differential counts of BAL cells were not altered by ESAT-6/ MWCNT but it is possible that ESAT-6 elicited phenotypic changes in macrophages which could account for the increased inflammatory mediators. For example, macrophages of the M-2 activation phenotype have been associated with pulmonary fibrosis [33,36]. Indeed the upregulation of PPAR $\gamma$ and reduction in IFN- $\gamma$ expression noted in BAL cells after ESAT-6/MWCNT instillation is more in line with an M-2 rather than an M1 macrophage activation phenotype [34,35]. These and the above results suggest that in analyzing mechanisms by which ESAT-6 alters pulmonary disease when combined with MWCNT, future studies must consider possible phenotypic changes induced by the combination in both macrophages and lymphocytes.

In summary, the instillation of mycobacterialESAT-6 with MWCNT alters the pulmonary landscape by exacerbating granulomatous disease and inducing fibrotic changes. Others have also shown that MWCNTinduced lung disease is exacerbated by the presence of bacterial lipopolysaccharide. A recent report documented the presence of carbon nanotubes in pediatric airways. These nanotubes were similar to those found in the dust and vehicle exhausts collected within the local environment and suggest that exposure to carbon nanotubes may be wide-spread within the population. Such findings combined with the current data suggest that an underlying carbon nanotube presence could adversely affect the outcome of microbial pulmonary disease in susceptible populations [3,37].

\section{Acknowledgement}

This work was supported by NIH grant ES 022462 and North Carolina Biotechnology Center grant BRG12-06. 
Citation: Malur A, Barna BP, Patel J, McPeek M, Wingard CJ, et al. (2015) Exposure to a Mycobacterial Antigen, ESAT-6, Exacerbates Granulomatous and Fibrotic Changes in a Multiwall Carbon Nanotube Model of Chronic Pulmonary Disease. J Nanomed Nanotechnol 6 : 340. doi:10.4172/2157-7439.1000340

\section{References}

1. De Volder MF, Tawfick SH, Baughman RH, Hart AJ (2013) Carbon nanotubes: present and future commercial applications. Science 339: 535-539.

2. Hirano S (2009) A current overview of health effect research on nanoparticles. Environ Health Prev Med 14: 223-225.

3. Kolosnjaj-Tabi J, Just J, Hartshorm K, Laoudi Y, Boudjemaa S, et al. (2015) Anthropogenic carbon nanotubes found in the airways of Parisian children. EBioMedicine

4. Lam CW, James JT, McCluskey R, Arepalli S, Hunter RL (2006) A review of carbon nanotube toxicity and assessment of potential occupational and environmental health risks. Crit Rev Toxicol 36: 189-217.

5. Lam CW, James JT, McCluskey R, Hunter RL (2004) Pulmonary toxicity of single-wall carbon nanotubes in mice 7 and 90 days after intratracheal instillation. Toxicol Sci 77: 126-134.

6. Shvedova AA, Kisin ER, Mercer R, Murray AR, Johnson VJ, et al. (2005) Unusual inflammatory and fibrogenic pulmonary responses to single-walled carbon nanotubes in mice. Am J Physiol Lung Cell Mol Physiol 289: L698-708.

7. Wang X, Katwa P, Podila R, Chen P, Ke PC, et al. (2011) Multi-walled carbon nanotube instillation impairs pulmonary function in C57BL/6 mice. Part Fibre Toxicol 8: 24.

8. Dong J, Porter DW, Batteli LA, Wolfarth MG, Richardson DL, et al. (2015) Pathologic and molecular profiling of rapid-onset fibrosis and inflammation induced by multi-walled carbon nanotubes. Arch Toxicol 89: 621-633.

9. Dymacek J, Snyder-Talkington BN, Porter DW, Mercer RR, Wolfarth MG, et al (2015) mRNA and miRNA regulatory networks reflective of multi-walled carbon nanotube-induced lung inflammatory and fibrotic pathologies in mice. Toxico Sci 144: 51-64

10. Huizar I, Malur A, Midgette YA, Kukoly C, Chen P, et al. (2011) Nove murine model of chronic granulomatous lung inflammation elicited by carbon nanotubes. Am J Respir Cell Mol Biol 45: 858-866.

11. Chen ES, Moller DR (2011) Sarcoidosis--scientific progress and clinica challenges. Nat Rev Rheumatol 7: 457-467.

12. Bresnitz EA, Stolley PD, Israel HL, Soper K (1986) Possible risk factors for sarcoidosis. A case-control study. Ann N Y Acad Sci 465: 632-642.

13. Izbicki G, Chavko R, Banauch GI, Weiden MD, Berger KI, et al. (2007) World Trade Center "sarcoid-like" granulomatous pulmonary disease in New York City Fire Department rescue workers. Chest 131: 1414-1423.

14. Prezant DJ, Dhala A, Goldstein A, Janus D, Ortiz F, et al. (1999) The incidence, prevalence, and severity of sarcoidosis in New York City firefighters. Chest 116: 1183-1193

15. Wu M, Gordon RE, Herbert R, Padilla M, Moline J, et al. (2010) Case report: Lung disease in World Trade Center responders exposed to dust and smoke: carbon nanotubes found in the lungs of World Trade Center patients and dust samples. Environ Health Perspect 118: 499-504.

16. Brownell I, Ramírez-Valle F, Sanchez M, Prystowsky S (2011) Evidence for mycobacteria in sarcoidosis. Am J Respir Cell Mol Biol 45: 899-905.

17. Carlisle J, Evans W, Hajizadeh R, Nadaf M, Shepherd B, et al. (2007) Multiple Mycobacterium antigens induce interferon-gamma production from sarcoidosis peripheral blood mononuclear cells. Clin Exp Immunol 150: 460-468.

18. Drake WP, Dhason MS, Nadaf M, Shepherd BE, Vadivelu S, et al. (2007) Cellular recognition of Mycobacterium tuberculosis ESAT- 6 and KatG peptides in systemic sarcoidosis. Infect Immun 75: 527-530.

19. Goyal B, Kumar K, Gupta D, Agarwal R, Latawa R, et al. (2014) Utility of B-cell epitopes based peptides of RD1 and RD2 antigens for immunodiagnosis of pulmonary tuberculosis. Diagn Microbiol Infect Dis 78: 391-397.

20. Hauck FR, Neese BH, Panchal AS, El-Amin W (2009) Identification and management of latent tuberculosis infection. Am Fam Physician 79: 879-886.

21. Dietrich J, Andersen C, Rappuoli R, Doherty TM, Jensen CG, et al. (2006) Mucosal administration of Ag85B-ESAT-6 protects against infection with Mycobacterium tuberculosis and boosts prior bacillus Calmette-Guerin immunity. J Immunol 177: 6353-6360.

22. Huizar I, Malur A, Patel J, McPeek M, Dobbs L, et al. (2013) The role of PPARî in carbon nanotube-elicited granulomatous lung inflammation. Respir Res 14: 7 .
23. Barna BP, Huizar I, Malur A, McPeek M, Marshall I, et al. (2013) Carbon nanotube-induced pulmonary granulomatous disease: Twist1 and alveolar macrophage M1 activation. Int J Mol Sci 14: 23858-23871.

24. Hörster R, Kirsten D, Gaede KI, Jafari C, Strassburg A et al. (2009) Antimycobacterial immune responses in patients with pulmonary sarcoidosis. Clin Respir J 3: 229-238.

25. O'Regan AW, Hayden JM, Body S, Liaw L, Mulligan N, et al. (2001) Abnormal pulmonary granuloma formation in osteopontin-deficient mice. Am J Respir Crit Care Med 164: 2243-2247.

26. Carpenter ZK, Williamson ED, Eyles JE (2005) Mucosal delivery of microparticle encapsulated ESAT- 6 induces robust cell-mediated responses in the lung milieu. J Control Release 104: 67-77.

27. Porter DW, Hubbs AF, Mercer RR, Wu N, Wolfarth MG, et al. (2010) Mouse pulmonary dose- and time course-responses induced by exposure to multiwalled carbon nanotubes. Toxicology 269: 136-147.

28. Tully G, Kortsik C, Höhn H, Zehbe I, Hitzler WE, et al. (2005) Highly focused $T$ cell responses in latent human pulmonary Mycobacterium tuberculosis infection. J Immunol 174: 2174-2184.

29. Richmond BW, Ploetze K, Isom J, Chambers-Harris I, Braun NA, et al. (2013) Sarcoidosis Th17 cells are ESAT- 6 antigen specific but demonstrate reduced IFN- $\hat{I}^{3}$ expression. J Clin Immunol 33: 446-455.

30. Oh K, Seo MW, Kim YW, Lee DS (2015) Osteopontin Potentiates Pulmonary Inflammation and Fibrosis by Modulating IL-17/IFN- $\left.\right|^{3}$-secreting T-cell Ratios in Bleomycin-treated Mice. Immune Netw 15: 142-149.

31. Berman JS, Serlin D, Li X, Whitley G, Hayes J, et al. (2004) Altered bleomycininduced lung fibrosis in osteopontin-deficient mice. Am J Physiol Lung Cell Mo Physiol 286: L1311-1318.

32. Craig VJ, Zhang L, Hagood JS, Owen CA (2015) Matrix Metalloproteinases as Therapeutic Targets for Idiopathic Pulmonary Fibrosis. Am J Respir Cell Mo Biol 53: 585-600.

33. Sun L, Louie MC, Vannella KM, Wilke CA, LeVine AM, et al. (2011) New concepts of IL-10-induced lung fibrosis: fibrocyte recruitment and M2 activation in a CCL2/CCR2 axis. Am J Physiol Lung Cell Mol Physiol 300: L341-353.

34. Bouhlel MA, Derudas B, Rigamonti E, Dièvart R, Brozek J, et al. (2007) PPARgamma activation primes human monocytes into alternative M2 macrophages with anti-inflammatory properties. Cell Metab 6: 137-143.

35. Chawla A (2010) Control of macrophage activation and function by PPARs Circ Res 106: 1559-1569.

36. Hussell T, Bell TJ (2014) Alveolar macrophages: plasticity in a tissue-specific context. Nat Rev Immunol 14: 81-93.

37. Cesta MF, Ryman-Rasmussen JP, Wallace DG, Masinde T, Hurlburt G, et al (2010) Bacterial lipopolysaccharide enhances PDGF signaling and pulmonary fibrosis in rats exposed to carbon nanotubes. Am J Respir Cell Mol Biol 43 142-151. 